\title{
Enhancing the lubricity of gas-to-liquid (GTL) paraffinic kerosene: impact of the additives on the physicochemical properties
}

Hani Ababneh ${ }^{1}$, Nasr Mohammad ${ }^{2}$, Hanif A. Choudhury ${ }^{2}$, Lei Zhang ${ }^{3}$, Rafiqul Gani ${ }^{4}$, Gordon McKay ${ }^{5}$ and Nimir Elbashir ${ }^{2^{*}}$ (D)

\begin{abstract}
Synthetic paraffinic kerosene (SPK) is an ultra-clean fuel with low aromatic content and negligible quantities of sulfur compounds. Although, SPK has a good potential to replace the conventional fuel Jet A-1, it also has some deficiencies. One of them is the low lubricity compared to its conventional counterpart Jet A-1. To improve the lubricity of SPK, three selected additives have been mixed with SPK at different concentrations. The lubricity of the samples was determined experimentally and the samples that meet the industry specifications have been studied further. The effect of the additives on the physicochemical properties, such as, density, flash point, freezing point, viscosity, and heat content, were investigated. Linoleic acid was found to be an excellent lubricity improver even at a very low concentration and its negative impact on the other physicochemical properties was found to be insignificant. Ethyl oleate also demonstrated significant improvement in lubricity at low concentrations but had a negative impact on the fuel's freezing point at high concentrations. Quinoline, at high concentrations, elevated the blend's freezing point above the acceptable limits. In parallel to the experimental campaign, a pre-existing mathematical modelling tool was utilized to predict the properties of interest. The lubricity model was successfully introduced into the mathematical model in order to improve the capabilities of the model. Linoleic acid sample showed the best improvement in lubricity of SPK with wear scar diameter of $417 \mu \mathrm{m}$; well below the ASTM D7566 maximum limit of $850 \mu \mathrm{m}$. The dual nature of this study facilitated the optimization of the physicochemical properties of the fuel samples.
\end{abstract}

Keywords: Synthetic paraffinic kerosene, Lubricity, Jet A-1, Physicochemical properties, Properties modelling

\section{Introduction}

The aviation industry is expanding with an annual growth rate of $\sim 6.2 \%$ over the last 5 years [1]. The projected annual growth for the next 30 years for passenger traffic and airline fleets is expected to be 4.7 and 3.5\%, respectively [1]. Therefore, the consumption of aviation

\footnotetext{
* Correspondence: nelabshir@tamu.edu

${ }^{2}$ Petroleum Engineering Program, Texas A\&M University at Qatar, P.O. Box 23874, Doha, Qatar

Full list of author information is available at the end of the article
}

fuel will be doubled in 2040 compared to the consumption in 2015 [2]. Currently, $\mathrm{CO}_{2}$ emissions from the aviation industry is about $2 \%$ and is expected to grow to $3 \%$ in 2050 [3]. Since emissions from aircraft occur at very high altitudes, therefore their effect in terms of Greenhouse Gas (GHG) contribution is compounded, especially for $\mathrm{NO}_{\mathrm{x}}$ and $\mathrm{SO}_{\mathrm{x}}$ emissions; however, these emissions have a significant negative impact on the airport's neighbourhood environment [4]. The rapid growth of the aviation industry and the stringent 
environmental regulations, in addition to the increase of fuel prices, have encouraged the industry to explore alternative jet fuels for turbine jet engines. Many international airlines have already started using blends of conventional jet fuel and synthetic jet fuel to compensate the increase in jet fuel price and their dwindling availability [5]. The synthetic fuels produced from the Gas to Liquid (GTL) process are ultra-clean as they lack aromatics and sulfur. Synthetic paraffinic kerosene (SPK) derived from the GTL process has been previously successfully blended with Jet A1 for use in the aviation industry [5].

Conventional jet fuel Jet A1 is the typical aviation fuel sourced from fossil fuel, it is a mixture of different hydrocarbons usually in the range $\mathrm{C} 8$ to $\mathrm{C} 16$ [6], these hydrocarbons are categorized into four groups: paraffins, cycloparaffins, olefins and aromatics in addition to small amounts of hydrocarbons that contain sulphur, nitrogen and oxygen [6]. The main difference between SPK and conventional jet fuel is that SPK does not contain aromatics and sulphur compounds and mainly consists of paraffinic hydrocarbons [5]. Paraffinic hydrocarbons have higher energy content when compared to other building blocks. Therefore, SPK fuel has a higher specific energy content than Jet A-1 [5]. On the other hand, since SPK is lacking sulphur, nitrogen, and oxygen compounds, SPK suffers from a lower lubricity and a lower density when compared to its conventional counterpart. An extremely important physical property of the fuel is lubricity. Lubricity is a measure of the fuel's ability to reduce friction and wear between the parts of the engine and fuel system, thereby, making it critical for extending the engine lifetime [7]. High lubricity fuel forms a continuous film that helps in minimizing the effect of friction on the metallic parts. On the other hand, films formed from low lubricity fuels might be too thin to provide enough protection or may not be distributed evenly on the surface of the metal [8]. When ultra-clean fuel was introduced to the engine and fuel systems, it resulted in the failure of the fuel injection systems leading to a decrease in the engine performance and in some cases complete engine failure [9]. This led to studies aimed at investigating the failures faced upon its application. It was found that the failure of engines and the pumping systems, while using ultra-clean fuel, was caused by the fuel's low lubricity. Aromatics, organic acids, nitrogen, oxygen, and sulfur compounds are reported to have the ability to improve the lubricity of a fuel [10]. Since SPK lacks these compounds, the fuel tends to have lower lubricity than Jet A-1 thereby causing excessive wear to the engine components $[10,11]$.

Lubricity additives are polar and active surface compounds with long hydrocarbon chains that contain an active group such as a carboxyl group or an ester group
[9]. These active polar groups react within the fuel to produce a protective film layer over the metal surface to protect it from friction and wear and tear [12]. The family of lubricity improvers includes carboxylic acids, amides, alcohols, ethers and esters as well as nitrogen and sulphur compounds $[9,10]$.

Anastopoulos et al. [13] reported an improvement in the lubricity of diesel fuel when adding carboxylic acids. They found that a concentration between 500 and 750 ppm is sufficient to yield comparable lubricity to that obtained when using amides and amines at higher doses [13]. In a study on the effect of lubricity, additives on the interaction between the fuel and the metal surface, Matzke et al. [10] concluded that losing nitrogen compounds such as quinoline from fuel is the main cause of poor lubricity [10]. In a separate study $\mathrm{Hu}$ et al. [9] found that tall oil fatty acid (TOFA) could be an excellent lubricity improver for diesel fuel even at concentrations lower than $500 \mathrm{ppm}$. Geller and Goodrum [14] experimentally determined that unsaturated fatty acid esters have a better performance in improving lubricity than saturated ones at concentrations up to $1 \mathrm{vol} \%$ of the fuel [14].

Several studies in past reported the lubricity of a fuel, types of additives that enhances the lubricity of the fuels, and techniques to measure lubricity of the diesel fuel except a few that reported the effect of these additives on jet fuels lubricity. Additionally, these studies focused only on the lubricity of the fuel while disregarding the other important physicochemical properties of the fuel that needs attention as well $[9,13,14]$. Currently, there are numerous published articles that aimed at building a mathematical model which can predict the physicochemical properties of a fuel blend.

Computer-aided technique is a relatively modern approach toward chemical product design. It include formulating the problem as an optimization model, in which the chemical structure, property prediction models, and process model equations are the constraints. By solving this model, the optimum product can be found [15]. For example, Conte et al. [16] implemented a computer-aided methodology for the design and verification of liquid products. In a different study, Cignitti et al. [17] proposed a framework for the design of pure and mixed chemical-based products using a computer-aided software. While, Jonuzaj et al. [18] formulated and solved Mixed Integer Non-Linear Programming (MINLP) problems to design solvent mixture. Choudhry et al. [19] has reported experimentally verified gasoline fuel surrogate design using a computer aided model-based technique MINLP. In a different study Choudhury et al. [20] have used the computer aided modelling tool to screen additive quickly and later experimentally validated the predictive ability of the 
computer model. The chemical properties and property models were called to solve the problem by producing a number of suitable candidates, which in their turn were calculated by a rigorous model and verified by experimental tests. They developed optimized surrogates which imitate the characteristics of GTL diesel and conventional diesel blends in accordance to ASTM D975 standards. Although there are voluminous literature available on predictive model development for designing fuel blends, no attempts were made to include the impact of the lubricity additives on the fuels physicochemical property to the best of our knowledge. In our earlier publications we have successfully developed a computer based model which can predict the physicochemical properties of the fuel and fuel blends $[19,20]$. Advancing the model to incorporate a comprehensive view on the effect of the lubricity additives on all critical properties allows the flexibility to explore different blend compositions without the need of physical formulation in the laboratory. Consequently, such a model decreases the effort and cost of preparation and purchase of the needed chemicals and equipment.

This study therefore aimed at addressing the lubricity challenge of SPK fuel while determining the trade-offs of these additives on the critical properties of the fuel. Additionally, improving the competences of an already developed model [19-21], that has been used to predict the fuel's lubricity as well as other properties is reported in this study.

\section{Methods}

This study was conducted in two stages. The first stage was to experimentally test the critical physicochemical properties of the fuels. The second stage was to forward samples compositions and properties to the mathematical modelling team at Dalian Technical University, where they utilized a previously developed mathematical modelling tool to predict the physicochemical properties of the fuel $[19,20]$. Later the data found in the lab and the predictions results obtained by the model were compared. Fuel samples were prepared as per the desired composition and their physicochemical properties were tested according to American Society for Testing of Materials (ASTM) standard methods that are listed in Table 1.

\section{Experimental campaign}

The experimental campaign was conducted at Texas A\&M University in Qatar at its state-of-the-art Fuel Characterization Laboratory. In order to understand the effect of lubricity additives on the SPK fuels physicochemical properties, fifteen fuel samples were prepared. Pure SPK fuel cut without any additive was not readily available in the market. Therefore, a total of $20 \mathrm{l}$ of GTL diesel were obtained from a local supplier and was fractionated to extract SPK fuel cut to be used in the subsequent investigations. To ensure that the extracted SPK meets the industry specification, various physicochemical characterization tests were conducted as listed in Table 1. Samples of SPK and lubricity improvers (additives) were prepared in their desired concentration and tests were conducted according to the various ASTM methods as listed in Table 1. The equipment items used to conduct the tests are listed in Table 2.

GTL diesel was fractionated by utilizing the Spinning Band Distillation System made by B/R Instrument USA. The operating conditions of the distillation column are given in Table 3.

Each diesel batch was added to the heating pot at the bottom of the fractionation column since the heating

Table 1 Selected key properties from ATM D7566 standard [7]

\begin{tabular}{|c|c|c|c|c|}
\hline Analyzed Property & ASTM Method & Unit & Minimum Limit & Maximum Limit \\
\hline Density & D4052 & $\mathrm{g} / \mathrm{cm}^{3}$ & 0.775 & 0.840 \\
\hline Viscosity at $-40^{\circ} \mathrm{C}$ & D445 & cSt & - & 12.00 \\
\hline Flash Point & D93 & ${ }^{\circ} \mathrm{C}$ & 38.0 & - \\
\hline Freezing Point & D5972 & ${ }^{\circ} \mathrm{C}$ & - & -40.0 \\
\hline Net Heat of Combustion & D240 & $\mathrm{MJ} / \mathrm{kg}$ & 42.8 & - \\
\hline Lubricity & D5001 & $\mathrm{mm}$ & - & 0.85 \\
\hline Distillation & D86 & & & \\
\hline $10 \%$ recovered, Temperature & & ${ }^{\circ} \mathrm{C}$ & - & 205 \\
\hline $50 \%$ recovered, Temperature & & ${ }^{\circ} \mathrm{C}$ & - & Report \\
\hline $90 \%$ recovered, Temperature & & ${ }^{\circ} \mathrm{C}$ & - & Report \\
\hline Final boiling point, Temperature & & ${ }^{\circ} \mathrm{C}$ & - & 300 \\
\hline Distillation residue & & $\%$ & - & 1.5 \\
\hline Distillation loss & & $\%$ & - & 1.5 \\
\hline
\end{tabular}


Table $\mathbf{2}$ List of instruments used for experimental campaign

\begin{tabular}{lll}
\hline Instrument & Test & ASTM test method \\
\hline PCS Automated BOCLE System & Lubricity Test & ASTM D5001 \\
Anton Paar DMA 4100 Density Meter & Density Test & ASTM D4052 \\
70Xi Cold Flow Properties Analyzer & Freezing Point Test & ASTM D5972 \\
Pensky-Martens SETA PM-93 & Flash Point Test & ASTM D93 \\
Parr 6200 Calorimeter & Heat Content Test & ASTM D240 \\
SVM 3000 Stabinger Viscometer & Viscosity Test & ASTM D445 \\
\hline
\end{tabular}

pot maximum capacity was 11 only. Each batch was 800 $\mathrm{ml}$. The fractionation process was started under the operating conditions given in Table 3 . The column system was set to produce two cuts, the first was the GTL SPK with a boiling point up to $240{ }^{\circ} \mathrm{C}$. The second cut was GTL diesel with a boiling point higher than $240{ }^{\circ} \mathrm{C}$. The SPK cut was collected using 8 collection tubes located after the condenser. From every GTL diesel batch about $310 \mathrm{ml}$ of SPK fuel were collected which is approx. $38 \%$ of the batch volume. Table 4 summarizes the fractionation process parameters.

The extracted SPK cuts from different batches were collected separately and tested to confirm their key properties (density, viscosity and distillation curve) for consistency. All the extracted SPK cuts were then mixed together to obtain a total 7.351 and the composition of the extracted SPK was determined using a gas chromatography-mass spectrometry (GC-MS) analyser.

Based on the literature review [10, 14, 22], three lubricity additives were selected for testing as summarized in Table 5.

A total of 15 SPK-additive samples were prepared, and their composition, concentration, and names are listed in Table 6.

Yue et al. [23] studied the influence of jet fuel's hydrogen/carbon $(\mathrm{H} / \mathrm{C})$ ratio and molecular weight on the fundamental properties of the fuel and it's supercritical cracking performance. They found that the value of $\mathrm{H} / \mathrm{C}$ is inversely proportional to the total content of aromatics and naphthenes in the fuel. In addition to being the main source of energy to power the aircraft's engine, jet fuel also operates as a coolant to absorb heat from various aircraft components such as the engine and the air frame [24]. Thus, it is important to study the performances of fuel at high temperatures and how it is

Table 3 Operating conditions for the fractionation column

\begin{tabular}{ll}
\hline Operating condition & Value \\
\hline Initial and final boiling points & $140-240{ }^{\circ} \mathrm{C}$ \\
Operating pressure & $20 \mathrm{mmHg}$ \\
Condenser Temperature & $20^{\circ} \mathrm{C}$ \\
Reflux Ratio & 2 \\
\hline
\end{tabular}

affected by the thermal cracking process and the formation of solid deposits such as coke [24].

Coke deposits on the surface of fuel system components degrades the performance of hydrocarbon fuels by increasing thermal resistance and fuel pressure drop. Also, large deposits of coke may lead to blocking the fuel passage [25, 26]. Yue et al. [23] reported that coke deposits decrease with the increase of $\mathrm{H} / \mathrm{C}$.

The $\mathrm{H} / \mathrm{C}$ ratio for the extracted SPK fuel was calculated using Eq. (2.1) [27]:

$$
\mathrm{H} / \mathrm{C}=\Sigma \mathrm{x}_{\mathrm{i}} \mathrm{H}_{\mathrm{i}} / \Sigma \mathrm{x}_{\mathrm{i}} \mathrm{C}_{\mathrm{i}}
$$

Where $x_{i}$ is the mole fraction of the component, and $\mathrm{H}_{\mathrm{i}}$ is the number of hydrogen atoms in the compound. (Eq. 2.1) is valid for density range of $0.7-0.827 \mathrm{~g} / \mathrm{cm}^{3}$. To find the molecular weight of the fuel, Eq. 2.2 was used [27].

$$
\mathrm{MW}_{\text {mix }}=\mathrm{x}_{\mathrm{i}} \mathrm{MW}_{\mathrm{i}}
$$

Where $\mathrm{X}_{\mathrm{i}}$ is the mole fraction of the component.

The lubricity values of the fuel samples were tested according to ASTM D5001 test method using PCS Automated BOCLE System. PCS BOCLE is a "Ball -onCylinder Lubricity Evaluator", BOCLE measures the lubricity of the fuel by immersing half of a ring in $50 \mathrm{ml}$ of the fuel sample. After fixing the temperature and humidity of the sample, a small metallic ball is lowered down to apply a pressure on the rotating ring, after 30 min of the applied pressure and due to friction between the ring and the ball, a scar will form on the ball surface at the point of contact. Next the ball is examined under the microscope and the wear scar diameter is measured [28]. Figure 1 illustrates the BOCLE test cell [29].

Table 4 Fractionation batch parameters

\begin{tabular}{lc}
\hline Parameter & Value \\
\hline Initial GTL Diesel volume per batch & $800 \mathrm{ml}$ \\
Fractionation time per batch & $3.5 \mathrm{~h}$ \\
Extracted SPK volume per batch & $305 \mathrm{ml}$ \\
Losses volume per batch & $<5 \mathrm{ml}$ \\
Fuel Recovery percentage & $38 \%$ \\
\hline
\end{tabular}


Table 5 CAS number and common usages for the selected lubricity additives

\begin{tabular}{lll}
\hline Chemical & CAS Number & Additive Usage \\
\hline Linoleic acid & $60-33-3$ & Carboxylic acid that has been used as a lubricity improver for Diesel fuel [18] \\
Ethyl Oleate & $111-62-6$ & A fatty acid ester used as an additive in bio-based lubricants [14] \\
Quinoline & $91-22-5$ & A heterocyclic aromatic with a nitrogen group [10]
\end{tabular}

\section{Mathematical Modelling}

Yunus et al. [21] reported a systematic methodology to design tailor-made blended products using computeraided techniques. They developed three supporting tools: a chemical database, a property model library, and a blend composition optimizer associated with their methodology. This methodology has been adopted by Choudhury et al. [20, 21] to design fuel surrogates for GTL diesel. In this study, the method reported by Yunus et al. [21] was used to estimate the lubricity of the fuel that meets the ASTM specifications. The first step was to define the problem: identify the product needs and translate them into physicochemical properties with target values that need to be matched. Here, the constraint for the new formulated SPK fuel samples was to meet the industry specifications for lubricity while meeting the standards for the other critical properties such as density $(\rho)$, viscosity $(\mu)$, freezing point $\left(T_{m}\right)$ flash point $\left(T_{f}\right)$, and heat content $\left(Q_{n}\right)$. The second step was to formulate the SPK samples with varying concentrations and compositions of the additives. The ingredients of the SPK fuel can be divided into main ingredients: (MI) and additives, where MI denotes the hydrocarbon content in the SPK fuel. The pure compound physicochemical properties have been obtained from databases, and

Table 6 Fuels samples and their concentrations

\begin{tabular}{llll}
\hline Sample Name & Additive & \multicolumn{2}{l}{ Additive Concentration } \\
\cline { 3 - 4 } & & ppm & Vol\% \\
\hline SPK 001 & - & 10 & - \\
SPK 002 & Linoleic Acid & 20 & - \\
SPK 003 & Linoleic Acid & 50 & - \\
SPK 004 & Linoleic Acid & 100 & \\
SPK 005 & Linoleic Acid & - & 0.5 \\
SPK 006 & Ethyl oleate & - & 1 \\
SPK 007 & Ethyl oleate & - & 2.5 \\
SPK 008 & Ethyl oleate & - & 5 \\
SPK 009 & Ethyl oleate & - & 10 \\
SPK 010 & Ethyl oleate & - & 0.5 \\
SPK 011 & Quinoline & - & 1 \\
SPK 012 & Quinoline & - & 2.5 \\
SPK 013 & Quinoline & - & 5 \\
SPK 014 & Quinoline & - & - \\
SPK 015 & Quinoline & - & - \\
\hline
\end{tabular}

any missing data were calculated using group contribution methods. For each sample, the selected additives and their compositions are fixed. Therefore, using the linear mixing rule for each property except lubricity, the mixture properties were predicted.

Next, the compositions of MI along with additives were fed into the model to assess its predictive capability. Finally, a comparison between the experimental and the model predicted data was made in order to verify the results of the model. That was achieved using a chemical product design software called ProCAPD. ProCAPD includes the data, models, methods and tools necessary to design a wide range of chemical products such as fuel blends in a fast, efficient, and reliable manner [30].

The following is an example of the equation used to calculate the sample's lubricity - the lubricity of the pure compound, $\lambda_{i}$ was calculated using Eq. (2.3) [31].

$$
\lambda_{i}=657.658-39.097 \mu-0.361 N+3.175 C y c
$$

Where $\lambda_{i}$ is the lubricity, $\mu_{\mathrm{i}}$ is the kinematics viscosity, $N_{i}$ is nitrogen content, $C y c_{i}$ is the cycloparaffins content of the compound in the fuel.

The lubricity of a mixture was calculated using Eq. (2.4).

$$
\log \left(\lambda_{m}\right)=\sum_{i} x_{i} \log \left(\lambda_{i}\right)
$$

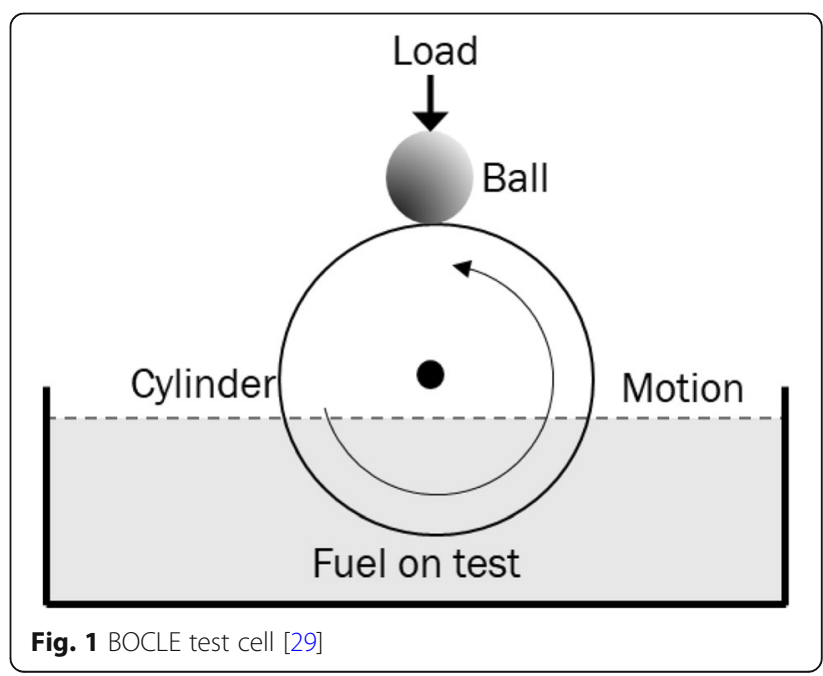


Where $\lambda_{m}$ is the lubricity of the mixture, $x_{i}$ is the mole fraction of compound $i, \lambda_{i}$ is the lubricity of compound $i$.

\section{Optimization model for the Design of Tailor-made Fuels} A MINLP optimization model was established to obtain the optimal fuel mixture. The property constraints were collected in Table 7. MINLP has proven to be a most general tool for modeling of non-linear problems with continues and discrete variables and has applications in a wide range of fields such as chemical engineering, finance, and manufacturing. MINLP combines the combinational difficulty of optimizing over discrete variable while handling challenges associated with non-linear functions. Thus MINLP has becomes the most general modelling criterion in optimization and includes both non-linear programing (NLP) and mixed integer linear programming (MILP) as sub problems [32].. The MINLP problem was solved using GAMS (General Algebraic Modeling System), SBB solver. More details on the optimization tool can be found in references $[15,20,30]$.

\section{Results and discussion}

The extracted SPK sample was analyzed by GC-MS and 31 components were identified. The components were grouped as families according to their carbon number. The total wt.\% distribution for the mixture is given in Fig. 2, which shows the distribution of identified iso- and normal-paraffinic compounds according to their carbon number. About $10 \%$ by weight of the components of the SPK cut could not be identified.

Table 8 gives the test results of the key properties for the extracted SPK fuel cut. The density of the SPK fuel cut is lower than the minimum value set by the ASTM D7566 specification and the wear scar diameter is higher than the maximum allowed value. On the other hand, the flash point, viscosity, freezing point, and heat content are all within the limits of the industry specifications.

The high percentage of normal paraffins (Fig. 2) explains the low density of the fuel cut and its high heat content. Normal paraffins ( $n$-paraffins) have lower densities and a higher heat content when compared to branched paraffins with the same carbon number [5].

Table 7 Property constraints of the fuel design problem

\begin{tabular}{lll}
\hline Properties & Lower bound & Upper bound \\
\hline Lubricity $(\mu \mathrm{m})$ & 0 & 500 \\
density $\left(\mathrm{g} / \mathrm{cm}^{3}\right)$ & 0.73 & 0.75 \\
Freezing point temperature $(\mathrm{K})$ & 0 & 234 \\
Flash point Temperature $(\mathrm{K})$ & 0 & 332 \\
Viscosity $(\mathrm{cSt})$ & 0 & 7.3 \\
Higher Heating Value $(\mathrm{MJ} / \mathrm{kg})$ & 47 & $+\infty$ \\
\hline
\end{tabular}

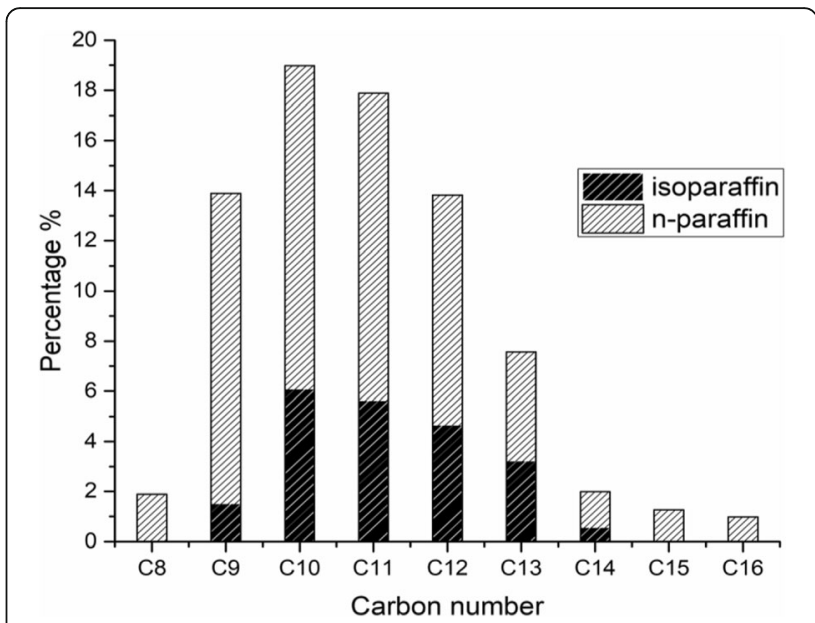

Fig. 2 The weight percentage of each carbon number in the SPK fuel cut

Additionally, the higher paraffinic content of the extracted SPK compared to Jet A1, results in the SPK fuel with a high $\mathrm{H} / \mathrm{C}$ as reported in Table 8.

In general, fuels with high $n$-paraffinic content tend to have low ignition delay time compared to fuels with high content of iso-paraffins and aromatics [33]. In addition to fuel composition, the fuel's volatility has a significant impact on delay times as the injected fuel forms droplets which evaporate before ignition. Low-boiling fuel tends to ignite faster, thus reducing the time delay. The distillation curve of the extracted SPK fuel is illustrated in Fig. 3, which shows initial and final boiling points of $163^{\circ} \mathrm{C}$ and $241{ }^{\circ} \mathrm{C}$, respectively. The curve satisfies the industry standards as the first $10 \%$ of volume was recovered at a temperature lower than $205^{\circ} \mathrm{C}$. Distillation residue and distillation losses were 1.4 and $1.3 \%$, respectively, both within the acceptable limits specified in ASTM D7566.

Since the extracted SPK fuel has high content of nparaffinic compounds and no aromatics, it is expected to have low delay times and preferable combustion behavior, especially when considering the initial boiling point

Table 8 Test results for key properties of SPK fuel cut

\begin{tabular}{llll}
\hline Tested Property & ASTM Method & Unit & SPK \\
\hline Density & D4052 & $\mathrm{g} / \mathrm{cm}^{3}$ & 0.7442 \\
Lubricity & D5001 & $\mu \mathrm{m}$ & 900 \\
Viscosity at $-40{ }^{\circ} \mathrm{C}$ & $\mathrm{D} 7042$ & $\mathrm{CSt}$ & 6.4085 \\
Flash Point & $\mathrm{D} 56$ & ${ }^{\circ} \mathrm{C}$ & 52 \\
Freezing Point & $\mathrm{D} 5972$ & ${ }^{\circ} \mathrm{C}$ & -41.5 \\
Net Heat of Combustion & $\mathrm{D} 240$ & $\mathrm{MJ} / \mathrm{kg}$ & 44.29 \\
Smoke Point & $\mathrm{D} 1322$ & $\mathrm{Mm}$ & No smoke \\
MW & - & $\mathrm{kg} / \mathrm{mole}$ & 160.46 \\
$\mathrm{H} / \mathrm{C}$ & - & - & 2.19 \\
\hline
\end{tabular}




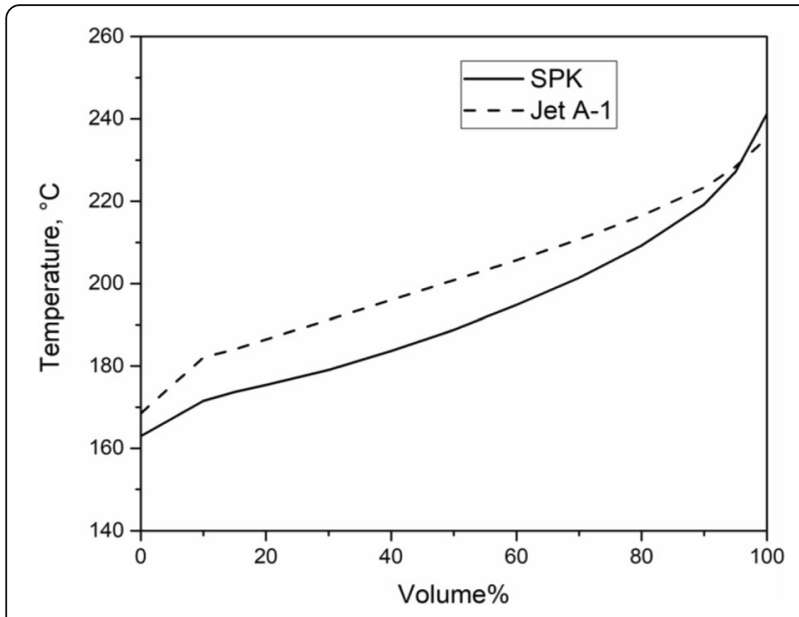

Fig. 3 Distillation curve for the extracted SPK fuel

of the fuel. Since aromatics and naphthenes form cokes more easily than paraffins during the cracking reaction [23], it is expected that the extracted SPK used in this study would have a lower tendency to form coke deposits at elevated temperatures and with lower cracking rates at high temperature. Thus, this makes SPK a safer fuel compared to its conventional counterpart.

Quinoline initially dissolves easily in the SPK; however, but it tends to precipitate out of the SPK after sometime creating two phases. This phenomenon indicates that quinoline has a low stability in the SPK fuel. No similar trends were observed in the linoleic acid or ethyl oleate samples.

\section{Lubricity trends of the fuel samples}

The wear scar diameter (WSD) of the extracted SPK was found to be $900 \mu \mathrm{m}$ and did not meet the ASTM D5001 specification of a jet fuel, i.e., $850 \mu \mathrm{m}$. Upon addition of linoleic acid as an additive in the extracted SPK, a significant improvement in the lubricity was observed as the WSD of the SPK dropped to $450 \mu \mathrm{m}$ from $900 \mu \mathrm{m}$. The lubricity results for linoleic acid mixed SPK are shown in Fig. 4a. It can be observed that the concentration of linoleic acid used in this study was sufficient to improve the lubricity of the SPK fuel. Similarly, both quinoline and ethyl oleate addition to the SPK resulted in ad substantial improvement on the lubricity value of the fuel samples as depicted in the Fig. 4b. However, linoleic acid has a pronounced effect on improving the lubricity value of the SPK samples compared to the quinoline and ethyl oleate. Only 0.001-0.01(vol\%) of linoleic acid was necessary to meet ASTM D5001 specification of lubricity compared to $0.5-10$ (vol\%) of quinolone and ethyl oleate. Referring to Fig. 4b, it is clear that the performance of ethyl oleate as a lubricity improver is superior to its quinoline counterpart at the same concentration. Analyzing the lubricity trends of all the fuel samples, we propose an exponential correlation (Eq-3.1) between additive concentration and fuels as given in Eq. 3.1.

$$
\begin{aligned}
& \text { WSD }=a-b * C^{d} \\
& \text { Where } \alpha=459.82,=-427.2, c=0.904 \text { and } d \\
& =\text { additive concentration }
\end{aligned}
$$

Comparison of the experimental results and the model predictions is shown in Fig. 4a. It can be observed that the model predicted values agree well with the experimental results for the linoleic acid samples. However, the model fails to predict the lubricity value of the extracted SPK fuel which has no additives. The variation in the model prediction was about 33\% from the experimental result for the extracted SPK. This could be attributed to the fact that the model used was developed for a conventional jet fuel but not for a SPK fuel.

In the case of quinoline and ethyl oleate samples, model predictions are in good agreement with the experimental data as given in Fig. 4b. However, a noticeable deviation in the model predictions was observed when the additive concentrations were varied between 2 and 4 (vol\%). The empirical model used to calculate the lubricity was developed for low-sulfur conventional diesel fuel using a standard method. The standard method for determining lubricity of diesel fuel was performed using the HFRR (High Frequency Reciprocating Rig) according to ASTM D6079. However, the test method used in this study utilized the BOCLE (Ball on Cylinder Lubricity Evaluator), following ASTM D5001 test method. The ASTM D5001 test is conducted at room temperature, while ASTM D6079 is performed at $60^{\circ} \mathrm{C}$, and with a lower load than the ASTM D5001 test.

As evident from the lubricity results, all the additives used in this study successfully improved SPK's lubricity to meet the ASTM D7566 specification of a Jet fuel. However, it is also important to ensure that these additives do not offer significant trade-offs when it comes to other critical fuel properties such as density, viscosity, freezing point, flash point and heat content which may lead to catastrophic consequences.

\section{Density trend of the fuel samples}

Density profiles of all the fuel samples are highlighted in Fig. 5a and $\mathrm{b}$. The density tests results revealed that all the tested fuel samples failed to meet the ASTM D7566 specification, which is specified as a minimum of $775 \mathrm{~g} /$ $\mathrm{cm}^{3}$. As discussed in the previous section, a very small concentration of linoleic acid was sufficient to improve the SPK fuel lubricity; however, there is no observable variation in the density profiles of the linoleic acid fuel samples. Linoleic acid has a higher density value of 

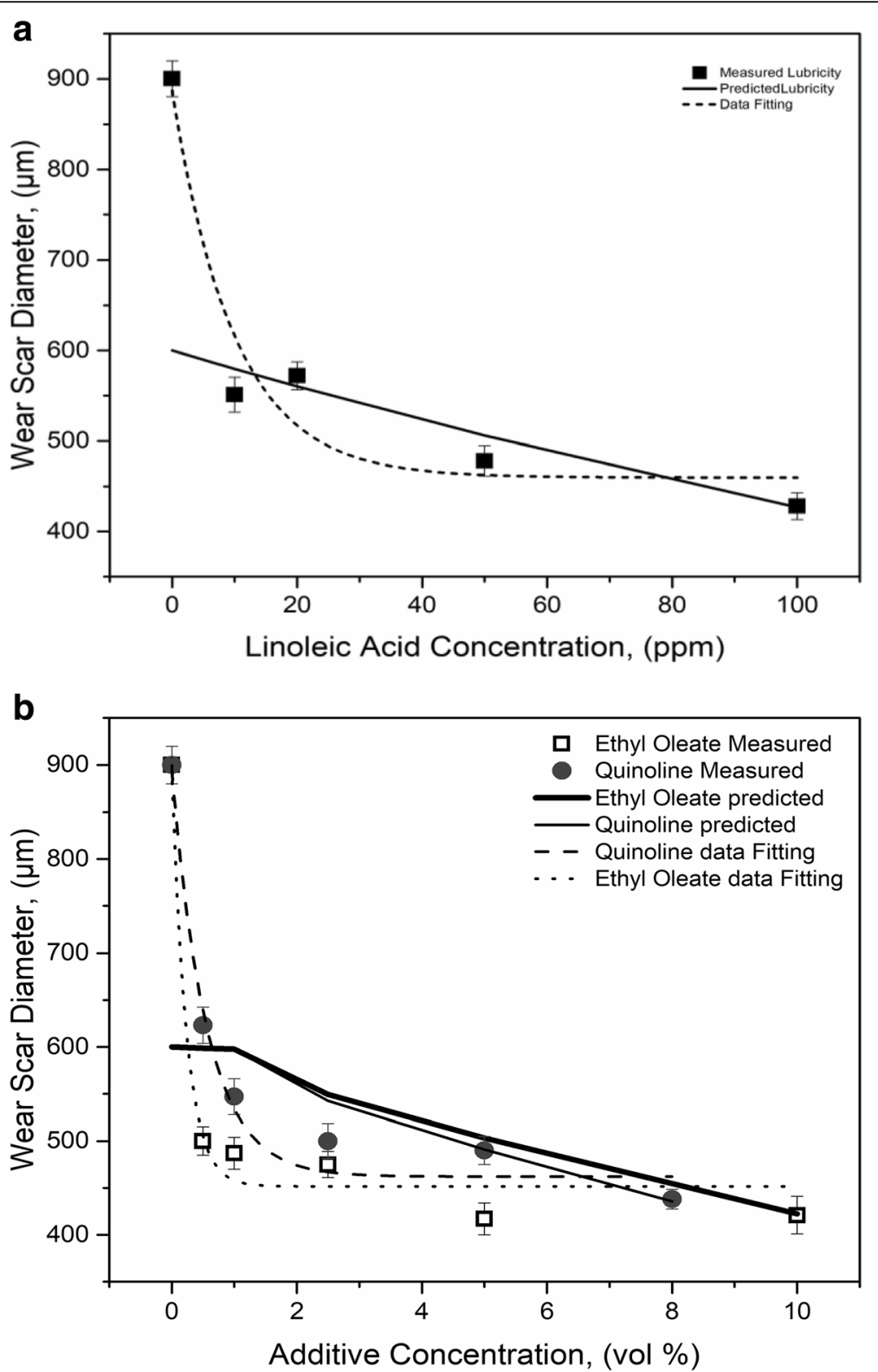

Fig. 4 a Comparing the experimental and predicted lubricity results of linoleic acid [31]. b Comparing the experimental and predicted lubricity results for quinoline and ethyl oleate samples [31]

$(900 \mathrm{~g} / \mathrm{L})$ compared to the extracted SPK. Nevertheless, a very small concentration of it as an additive in the fuel was not sufficient to cause any apparent increase in the density of the sample.

The model predicts a negligible change in the density value for the linoleic acid samples which is the same trend found in the experimental result as shown in Fig. 5a. This could be attributed for the same reason: the small contractions of linoleic acid added were not sufficient to cause an increase in density of the sample.
Density predictions for ethyl oleate and quinolone samples correspond well with experimental results. The differences between the model prediction and measured densities do not exceed $2 \%$. However, there is a subtle difference in the density trend predicted by the model compared to the trend obtained in the experiments, which warrants fine tuning of the model parameters.

By extrapolating the density trend for quinolone sample, we estimate that a concentration beyond $25 \mathrm{vol} \%$ will meet the ASTM specification for density and lubricity. Similarly, ethyl oleate will require a much higher 

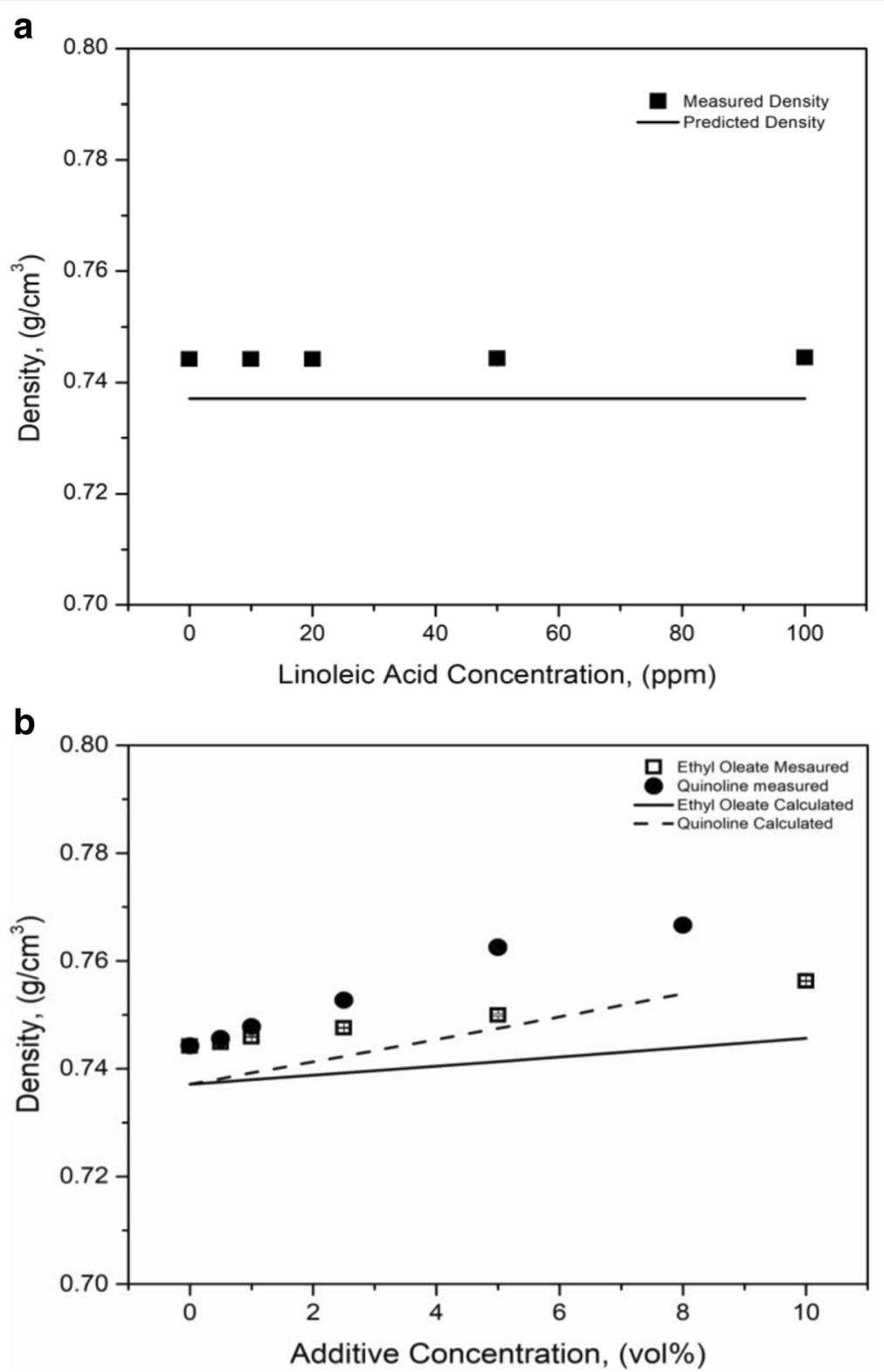

Fig. 5 a Comparing the experimental and predicted density results of linoleic acid samples [21]. b Comparing the experimental and predicted density results of quinoline and ethyl oleate samples [21]

concentration to meet the ASTM specification for density and lubricity.

\section{Freezing point trend of the fuel}

The freezing point is one of the most crucial properties of jet fuel, which ensures the proper operation of the fuel system at an elevated altitude and thus has severe implications when it comes to the safe operation of the aircraft. It is important to note that any additive used to boost a particular property of the fuel should not negatively affect the freezing point. The ASTM-D7566 specification for maximum freezing point is $-40{ }^{\circ} \mathrm{C}$ for jet fuels. Mixing linoleic acid with SPK has no significant effect on the freezing point of the SPK samples, as shown in Fig. 6a. This was further confirmed in the modelling part. The linear mixing rule was used to estimate the freezing point, since the concentration of the added linoleic acid was small. Figure 6a illustrates that model predictions and experimental results are within the margin of error for the device.

Quinoline and ethyl oleate, on the other hand, resulted in a sample failing to meet ASTM D7566 specification for freezing point at concentrations beyond $2.5 \mathrm{vol} \%$, as illustrated in Fig. 6b.

The model predictions for freezing point at a lower additive concentration below 2.5 vol\% agrees well with 

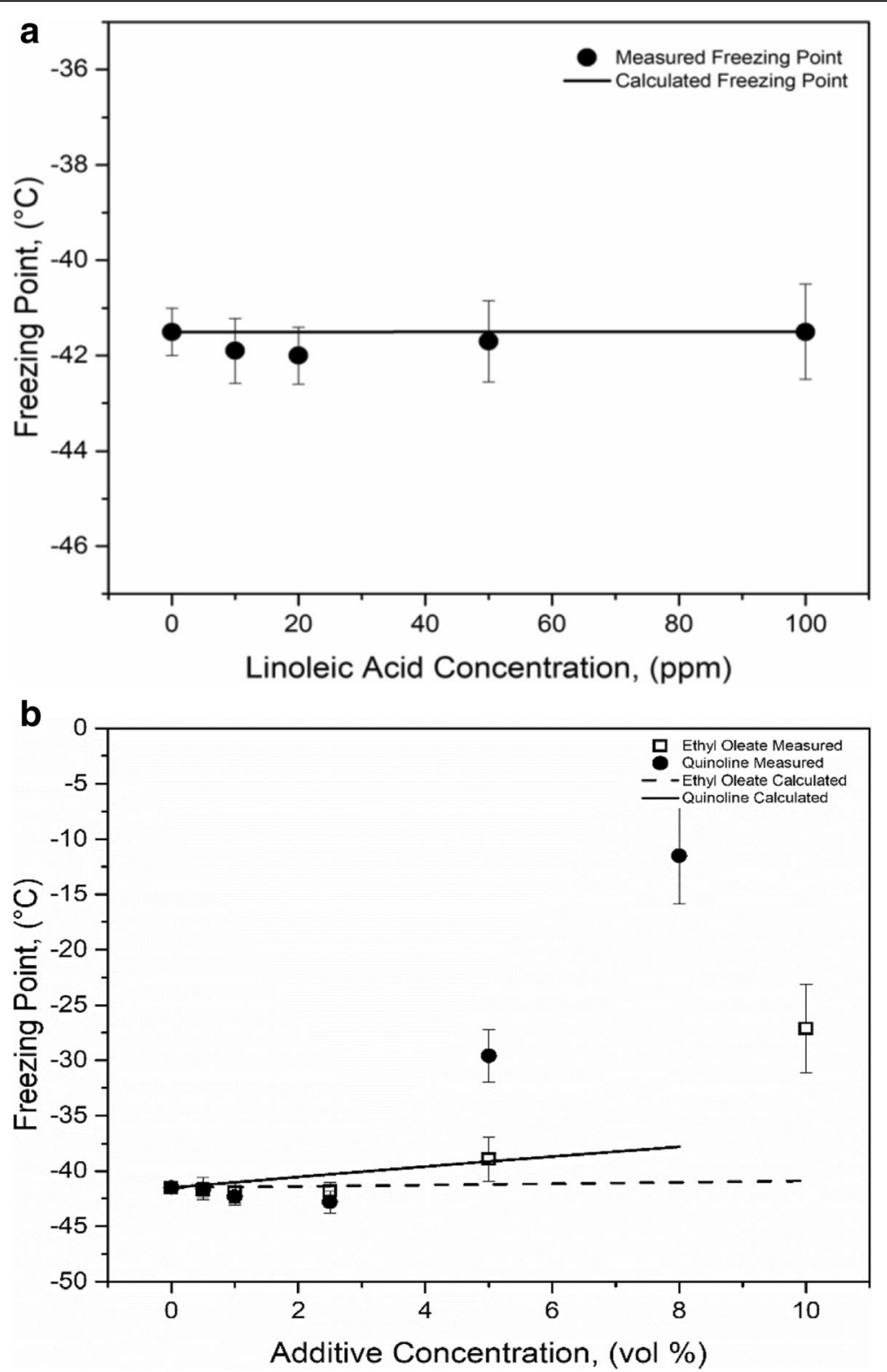

Fig. $\mathbf{6}$ a Comparing the experimental and computational freezing point of linoleic acid samples. b Comparing the experimental and computational freezing point results of ethyl oleate and quinoline samples

experimental value, as seen in Fig. 6b. At concentrations beyond $2.5 \%$ of the sample volume, model predictions deviated significantly. Both quinolone and ethyl oleate have higher melting points of $-15^{\circ} \mathrm{C}$ and $-32^{\circ} \mathrm{C}$ than the extracted SPK, respectively. The comparison shows that a correction term for the higher concentration needs to be added to the linear mixing rule as at higher concentrations, the effect of composition on the freezing point is non-ideal. Therefore, dissolution is expected below their melting points. As the concentration is increased beyond $2.5 \mathrm{vol} \%$, there is a probable dissolution of the additives in the fuel sample resulting in a non- homogeneous mixture when the temperature is below subzero conditions [7]. On the other hand, the freezing point model used in this study does not account for the solubility characteristics of the additive in the fuel, which is more pronounced when the temperature drops to subzero levels, thus explaining the deviation between the model predictions and experimental data.

\section{Flash point trends of fuel samples}

The flash point of the extracted SPK fuel was measured to be $52^{\circ} \mathrm{C}$ which is well above the minimum required limit by ASTM D1655 and D7566 of $38^{\circ} \mathrm{C}$. Figures 7a 

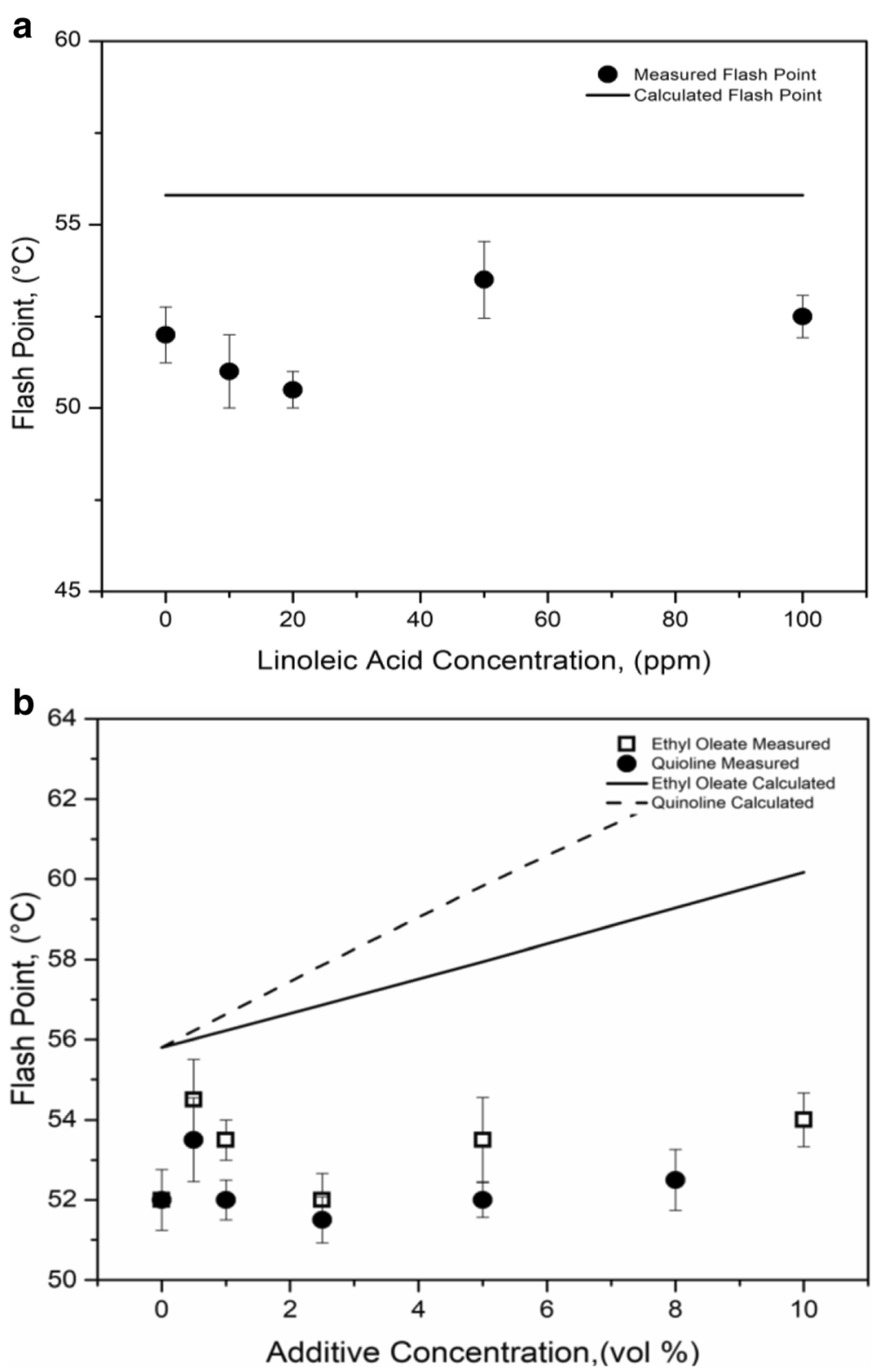

Fig. 7 a Comparing the experimental and computational flash point results of linoleic acid samples. $\mathbf{b}$ Comparison of the experimental and computational flash point results of ethyl Oleate and quinoline samples

and $\mathrm{b}$ show that all the tested samples have flash points in the range of $51{ }^{\circ} \mathrm{C}$ to $54.5^{\circ} \mathrm{C}$. No clear relationship between the additive concentration and the flash point could be established; especially given that the variation in the temperature for each additive was small and fairly insignificant. This result is in agreement with a previous study by Elmalik et al. [5].

Utilizing the linear mixing rule for estimating the flash point for linoleic acid samples, it can be noticed in Fig. 7a how small is the variation between the mathematical and experimental data; the small difference is due to the margin of error of the Pensky-Martens SETA PM-93 device. The model predicted a linear trend for the flash point of the tested fuel samples. In the case of ethyl oleate and quinoline samples, the mathematical model used to predict the flash points used a group contribution method reported by Kalakul et al. [30]. Later Choudhury et al. [20] successfully reported a flash point prediction method of surrogate diesel using the same model with a maximum error of $28.34 \%$. This study reports the maximum error in the model prediction for flash point to be $\sim 15 \%$, which could due to the assumption of the activity coefficient to be unity. Therefore, an improvement in the model predictions could be achieved by considering the activity coefficient of each of the constituent components in the fuel sample. 


\section{Viscosity trends of fuel samples}

The extracted SPK has a viscosity of $6.40845 \mathrm{cSt}$ at $40^{\circ} \mathrm{C}$, which meets the ASTM D7566 specification. As per ASTM D7566 maximum viscosity at $-40{ }^{\circ} \mathrm{C}$ is 12 cSt. None of the additives used in this study have changed the viscosity of the samples under test to an unacceptable level of ASTM D7566 specifications. The viscosity value of all the fuel samples are depicted in Fig. $8 \mathrm{a}$ and b. Adding linoleic acid to the extracted SPK had no significant effect on its viscosity as the difference between the viscosities of extracted SPK and the additized fuel samples are small. The model predictions for the viscosity of the linoleic acid samples are in excellent agreement with the data obtained in the laboratory as depicted in Fig. 8a. As mentioned in the freezing point tend of the fuel, the linoleic acid is added in part parts million ( $\mathrm{ppm}$ ) to the SPK and the subtle variation in the concentration is beyond the detection limit of the instrument used to measure the viscosity value.

The effect of ethyl oleate on the viscosity value was the highest compared to both quinolone and linoleic acid. However, the maximum concentration of the ethyl oleate used in this study (10 vol\%) did not increase the viscosity beyond its acceptable limits set by ASTM D7566. Therefore, all the tested fuel samples met the industry standards, despite the fact that the additives did
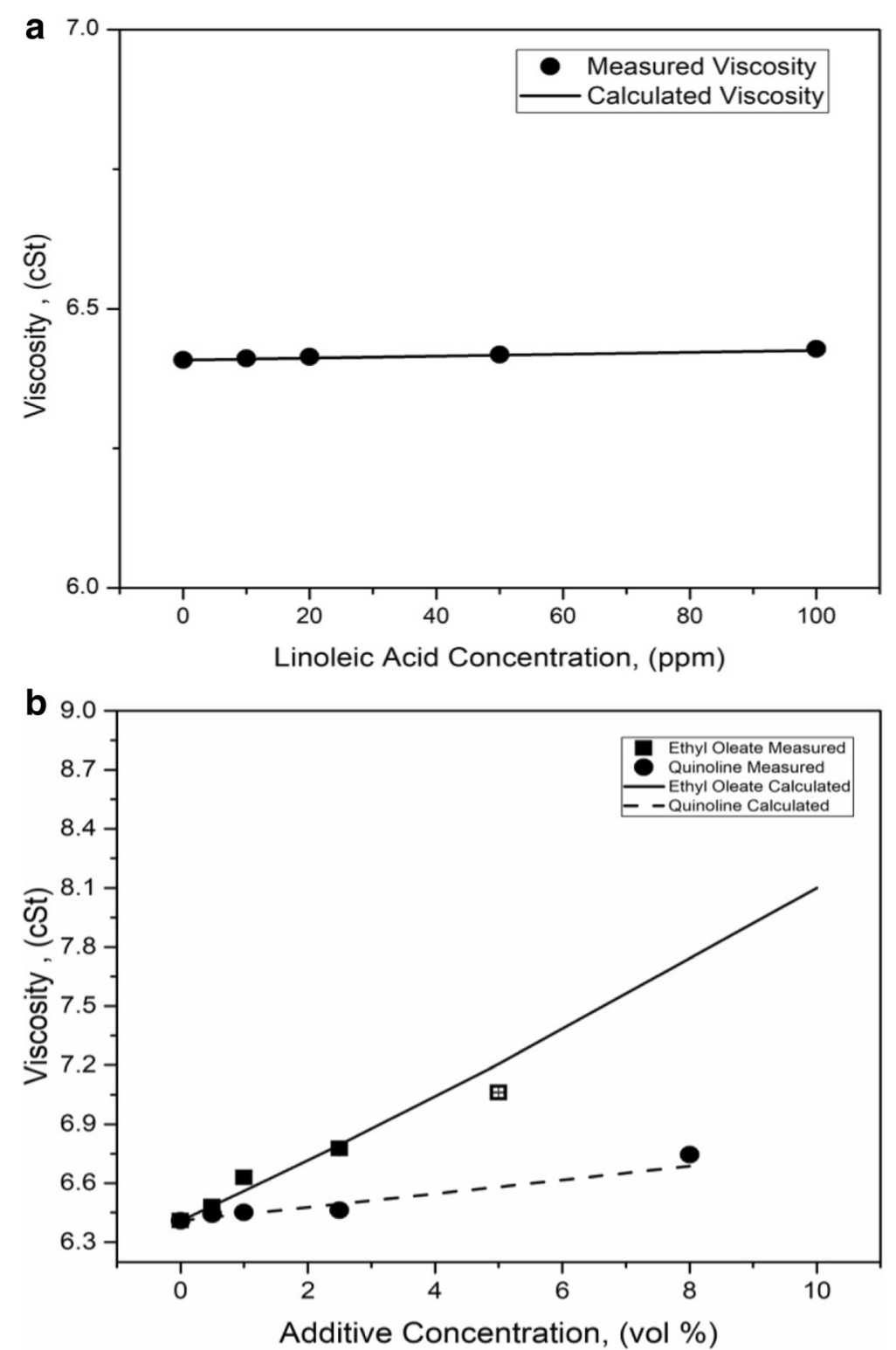

Fig. 8 a Comparing the experimental and computational viscosity at $-40{ }^{\circ} \mathrm{C}$ results of linoleic acid samples [20]. b Comparing the experimental and model predicted viscosities for ethyl oleate and quinolone samples [20] 
increase the viscosity marginally. Model predictions of viscosity for quionoline and ethyl oleate are in good agreement with the experimental results as depicted in the Fig. $8 \mathrm{~b}$.

\section{Net heat content trends of fuel samples}

The extracted SPK fuel meets the target for net heat content as specified in ASTM D7566 (min. of 42.8 MJ/ $\mathrm{kg}$ ). All the tested samples were found to have a lower heat content than the extracted SPK fuel. Figure 9 depicts the net heat profiles for ethyl oleate and quinoline samples. The decrease in the net heat content of the fuel was more noticeable with the increase in their concentration in the fuel samples. It can be observed that the heat contents follow a linear correlation with the additive concentration, which is in agreement with previous studies in literature [20,21].

The model predicted net heat content values are compared with the experimental data and are shown in Fig. 9. It is clear from Fig. 9 that the model predictions are in good agreement with the experimental data.

It is expected that the addition of the ethyl oleate and quinoline to the SPK would result in an increase in the delay time of the fuel, since both are considered highly stable compounds; especially quinoline with its stable rings. On top of that, their addition to the SPK increases its viscosity, therefore the SPK would have larger droplets when injected into the engine. It is worth noting that the $\mathrm{H} / \mathrm{C}$ ratio of ethyl oleate and quinoline samples are lower than those of the SPK as depicted Fig. 10. Therefore, these fuel samples will tend to form more coke as a result of cracking reactions at elevated temperatures.

\section{Optimization results}

The MINLP optimization model predicted that the optimal mixture which would satisfy ASTM D7655 specification is the SPK-ethyl oleate sample with $5.6 \mathrm{vol} \%$ of ethyl oleate as given in Table 9. The model predicted an optimum fuel sample that closely resembles an FCL009 composition, which is a sample of extracted SPK and ethyl oleate. The physicochemical properties, which have been predicted for the optimum sample, are in good agreement with the properties of the FCL009 fuel sample which has the best lubricity characteristics among all other tested fuels. The Optimization model developed in this study demonstrated a promising potential for future studies in designing future new generation ultra-clean fuels.

\section{Conclusions}

In this study three lubricity additives ethyl oleate, linoleic acid and quinoline were tested in the laboratory and the results revealed that all these additives improve the lubricity of the SPK fuel. An exponential correlation between additive concentration and the lubricity of the fuel was observed for the tested samples. Linoleic acid was found to have a profound impact of the SPK fuel lubricity even at concentrations as low as $10 \mathrm{ppm}$, while the two other additives required higher doses to achieve the same results. The freezing point of the fuel containing more than $2.5 \mathrm{vol} \%$ of ethyl oleate and quinoline failed to meet the ASTM D7655 specification despite meeting

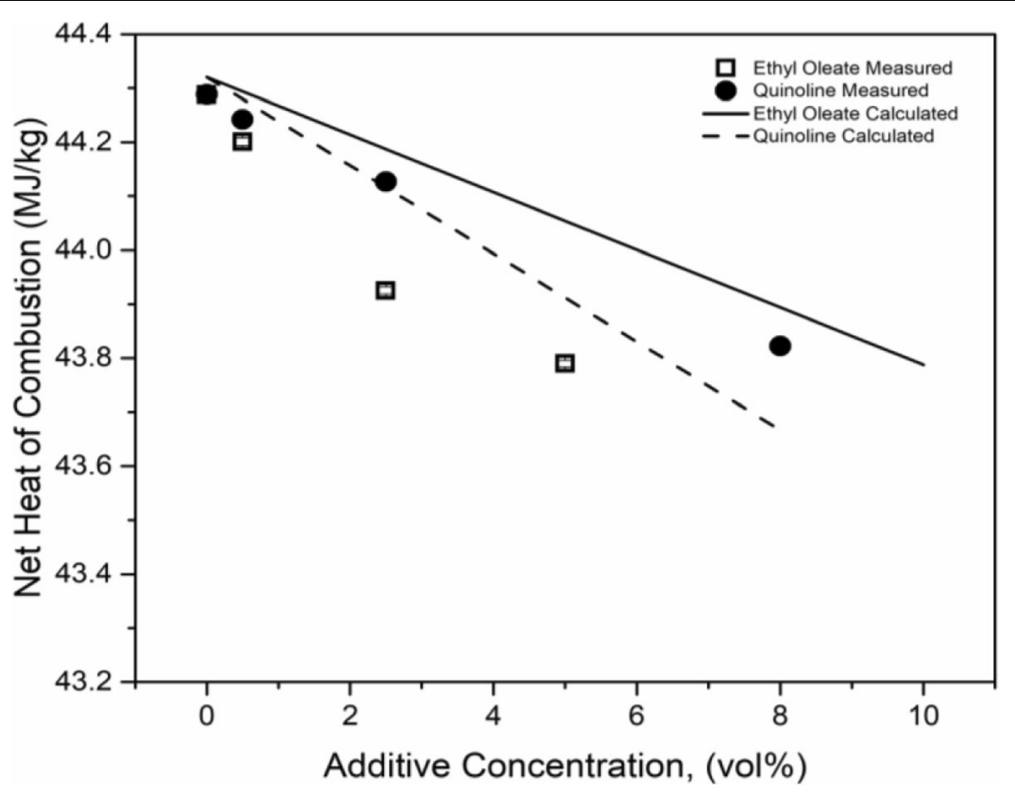

Fig. 9 Comparing the experimental vs. computational net heat content results of ethyl oleate and quinoline samples [21] 


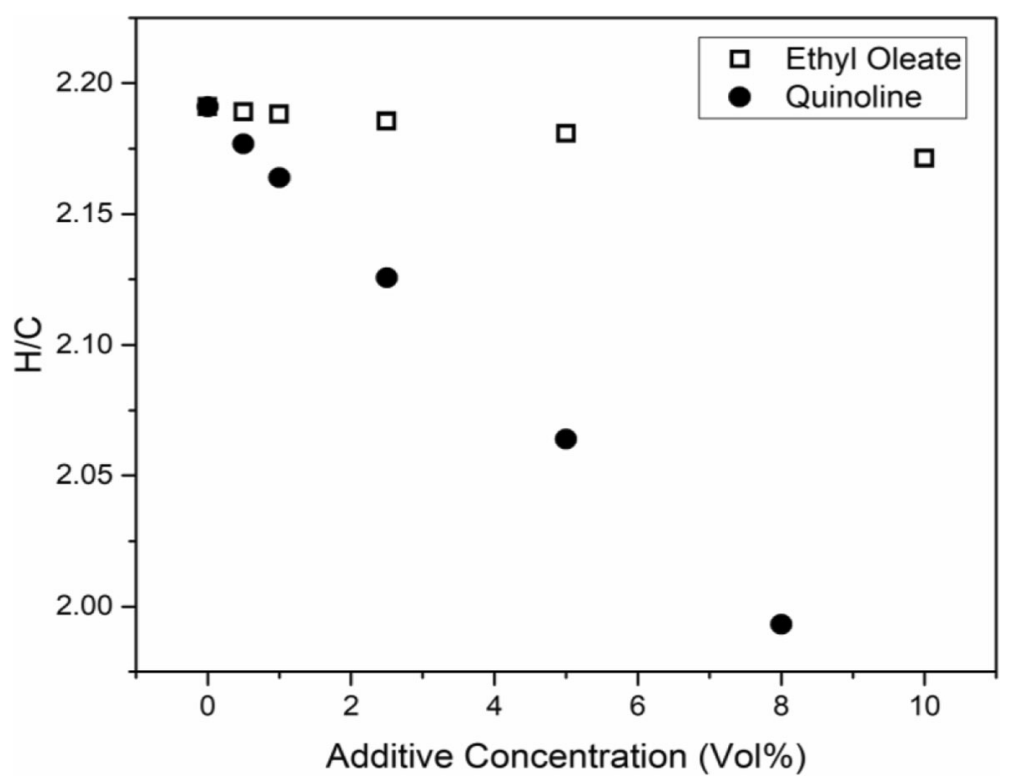

Fig. 10 Fuel $\mathrm{H} / \mathrm{C}$ variation with increasing additive concentration

the lubricity characteristics of the fuel. Higher concentration of the ethyl oleate beyond $2.5 \%$ should be avoided in SPK as it poses the risk of producing a fuel mixture that freezes at higher altitude where external temperature may drop below $-38^{\circ} \mathrm{C}$. The aromatic additive quinoline was found to have pronounced effect on decreasing the $\mathrm{H} / \mathrm{C}$ of the fuel compared to an aliphatic one. A lower $\mathrm{H} / \mathrm{C}$ value of the fuel will tend to have lower net heat value and a higher coke formation tendency leading to clogging of the fuel system. Thus, the aromatic additive should not be utilized for improving aviation fuels lubricity. In the modeling analysis, the lubricity data was added successfully to the model architecture to improve the model predictions for the physicochemical properties of the fuel. However, the model prediction of lubricity at lower additive

Table 9 Optimization results of the MINLP model

\begin{tabular}{lll}
\hline Properties & Optimization Model & $\begin{array}{l}\text { Lab testing data } \\
\text { (FCLO09) }\end{array}$ \\
\hline Additives & Ethyl oleate & $\begin{array}{l}\text { Ethyl oleate } \\
\text { Fuel }\end{array}$ \\
Concentration (Vol\%) & 5.6 & Extracted SPK \\
Lubricity $(\mu \mathrm{m})$ & 493.48 & 5 \\
Density $\left(\mathrm{g} / \mathrm{cm}^{3}\right)$ & 0.749 & 417 \\
Freezing point $\left({ }^{\circ} \mathrm{C}\right)$ & -42.2 & 0.75 \\
Flash point $\left({ }^{\circ} \mathrm{C}\right)$ & 58.8 & -38.9 \\
Viscosity $(\mathrm{CSt})$ & 7.3 & 53.5 \\
Gross Heat Content $(\mathrm{MJ} / \mathrm{kg})$ & 44.02 & 7.06 \\
\hline
\end{tabular}

concentrations were not very precise. Also, model prediction for the fuel sample without any additive was also showing a significant deviation. Therefore, studies focused on developing a model for predicting lubricity specific to jet fuel needs to be conducted in future.

The models for the predictions for viscosity, density and heat content agrees well with the experimental data. However, freezing point and flash point models require fine tuning by introducing new parameters to account for the non-ideality.

Finally, the computational modeling results agree with the experimental results corroborating MINLP to be a credible tool to optimize SPK fuel samples.

As a follow-up of this study, we recommend an experimental protocol to improve the density of the fuel by conducting a separate study. The goal of such a study would be to find suitable additives or blending components that can improve the density of the SKP fuel. This would help realizing the use of pure SPK fuels directly into commercial jet engines.

\section{Nomenclature}

$\rho$ Density

$\mathrm{H}_{\mathrm{i}}$ Number of hydrogen atoms in the compound $\mathrm{i}$

$C_{i}$ Number of hydrogen atoms in the compound $i$

$\mathrm{MW}_{\mathrm{i}}$ Molecular weight of component i

$\mathrm{MW}_{\text {mix }}$ Molecular weight of the fuel mixture

$\mu$ Viscosity

$\mathrm{T}_{\mathrm{m}}$ Freezing point

$\mathrm{T}_{\mathrm{f}}$ Flash Point

$\mathrm{Q}_{\mathrm{n}}$ Heat content

$\lambda_{i}$ Lubricity of component $\mathrm{i}$ 
$\mu_{\mathrm{i}}$ kinematics viscosity of component $\mathrm{i}$

$\mathrm{N}_{\mathrm{i}}$ Nitrogen content

$\mathrm{Cyc}_{\mathrm{i}}$ Cycloparaffins content of the compound $\mathrm{i}$ in the fuel

$\lambda_{\mathrm{m}}$ lubricity of a mixture

WSD Wear scar diameter

$\mathrm{d}$ Additive concentration

\section{Supplementary information}

Supplementary information accompanies this paper at https://doi.org/10. 1186/s42480-020-00032-2.

Additional file 1: Table S1. Experimental results of Samples. Table S2. Computational modeling results of samples.

\section{Abbreviations}

SPK: Synthetic paraffinic kerosene; ASTM: American society for testing and materials; GHG: Greenhouse gas; GTL: Gas to liquid; GC-MS: Gas chromatography-mass spectrometry; BOCLE: Ball -on-cylinder lubricity evaluator; MINLP: Mixed integer nonlinear programming; GAMS: General algebraic modeling system; HFRR : High frequency reciprocating rig; $(\mathrm{H} /$ C): Hydrogen to carbon ratio

\section{Acknowledgements}

The authors would like to acknowledge Hamad Bin Khalifa University for a research scholarship award, and to all Texas A\&M University at Qatar and the Fuel Characterization Lab staff.

\section{Authors' contributions}

$\mathrm{H}$. Ababneh and N. Mohammed conducted the experimental campaign, D. L. Zhang and Dr. R. Gani developed the computational model, and Dr. H.A. Choudhury designed the analysis. Dr. G. McKaye and Dr. N Elbashir supervised all the work. All authors have contributed to the drafting and agreed to the final version of the manuscript.

\section{Funding}

Not applicable

\section{Availability of data and materials}

All data generated or analyzed during this study are included in this article.

\section{Competing interests}

The authors declare that they have no competing interests

\section{Author details}

${ }^{1}$ Chemical Engineering Department, College of Engineering, Qatar University, 2713 Doha, Qatar. ${ }^{2}$ Petroleum Engineering Program, Texas A\&M University at Qatar, P.O. Box 23874, Doha, Qatar. ${ }^{3}$ Institute of Chemical Process Systems Engineering, School of Chemical Engineering, Dalian University of Technology, Dalian 116024, China. ${ }^{4}$ PSE for SPEED, Skyttemosen 6, DK 3450 Allerod, Denmark. ${ }^{5}$ Sustainable Energy Program, Division of Sustainable Development, College of Science and Engineering, Hamad Bin Khalifah University, P.O 5825 Doha, Qatar.

Received: 24 April 2020 Accepted: 22 July 2020

Published online: 06 August 2020

\section{References}

1. Boeing. Current Market Outlook 2017-2036. 2017; Available from: http:// www.boeing.com/resources/boeingdotcom/commercial/market/currentmarket-outlook-2017/assets/downloads/2017-cmo-6-19.pdf. Accessed 13 Sept 2019.

2. Energy US. International Energy Outlook 2017 Overview. Int Energy Outlook 2017; IEO2017(2017):143. Available from: https://www.eia.gov/outlooks/ieo/ pdf/0484(2017).pdf.

3. IATA. Fact Sheet Climate Change \& CORSIA. IATA online. 2017;2016-7. Available from: https://www.iata.org/pressroom/facts figures/fact sheets/ Documents/fact-sheet-climate-change.pdf. Accessed 15 Oct 2019.
4. Civil Aviation Authority CA. Information on aviation's environmental impact. 2017; Available from: https://publicapps.caa.co.uk/docs/33/CAP1524 Environmentallnformation29032017.pdf. Accessed 17 Oct 2019.

5. Elmalik EE, Raza B, Warrag S, Ramadhan H, Alborzi E, Elbashir NO. Role of hydrocarbon building blocks on gas-to-liquid derived synthetic jet fuel characteristics. Ind Eng Chem Res. 2014:53(5):1856-65.

6. Blakey S, Rye L, Wilson CW. Aviation gas turbine alternative fuels: a review. Proc Combust Inst. 2011;33(2):2863-85.

7. ASTM. Standard Specification for Aviation Turbine Fuels. Annu B ASTM Stand. 2010;1-16. Available from: https://www.astm.org/Standards/ D7566.htm.

8. Anastopoulos G, Kaligeros S, Schinas P, Zannikou Y, Karonis D, Zannikos F. The impact of fatty acid Diisopropanolamides on marine gas oil lubricity. Lubricants. 2017:5(3):28.

9. Hu Z, Zhang L, Li Y. Investigation of tall oil fatty acid as antiwear agent to improve the lubricity of ultra-low sulfur diesels. Tribol Int. 2017;114 57-64.

10. Matzke M, Jess A, Litzow U. Polar nitrogen-containing aromatic compounds as carriers of natural diesel lubricity. Fuel. 2015;140:770-7.

11. Moses CA. Semi-Synthetic Jet Fuels CRC Report. 2008;(September). Available from: http://www.ncfap.org/documents/biofuels aviation/Comparison\%2 0of\%20SSJF\%20-\%20CRC\%20Final.pdf. Accessed 20 Nov 2019.

12. Anastopoulos G, Kalligeros S, Schinas P, Zannikos F. Effect of dicarboxylic acid esters on the lubricity of aviation kerosene for use in $\mathrm{Cl}$ engines. Friction. 2013;1(3):271-8.

13. Anastopoulos G, Lois E, Karonis D, Kalligeros S, Zannikos F. Impact of oxygen and nitrogen compounds on the lubrication properties of low sulfur diesel fuels. Energy. 2005;30:415-26.

14. Geller DP, Goodrum JW. Effects of specific fatty acid methyl esters on diesel fuel lubricity. Fuel. 2004:83(17-18):2351-6.

15. Zhang L, Kalakul S, Liu L, Elbashir NO, Du J, Gani R. A computer-aided methodology for mixture-blend design. Applications to tailor-made design of surrogate Fuels. Ind Eng Chem Res. 2018;57(20):7008-20.

16. Conte E, Gani R, Ng KM. Design of Formulated Products: a systematic methodology. AICHE J. 2011;57(1):2431-49.

17. Cignitti S, Zhang L, Gani R. Computer-aided framework for Design of Pure. Mixed and Blended Products. 2015;37:2093-8.

18. Jonuzaj S, Akula PT, Kleniati PM, Adjiman CS. The formulation of optimal mixtures with generalized disjunctive programming: A solvent design case study. AlChE J. 2016:62:1616-33.

19. Choudhury HA, Intikhab S, Kalakul S, Gani R, Elbashir NO. Integration of computational modeling and experimental techniques to design fuel surrogates. J Natural Gas Sci Engin. 2017:55:585-94.

20. Choudhury HA, Intikhab S, Kalakul S, Khan M, Tafreshi R, Gani R. Designing a surrogate fuel for gas-to-liquid derived diesel. Energy Fuel. 2017;31(10): 11266-79.

21. Yunus NA, Gernaey KV, Woodley JM, Gani R. A systematic methodology for design of tailor-made blended products. Comput Chem Eng. 2014 66:201-13.

22. Johnson DW, Flake M, Adams R. Determination of corrosion inhibitor lubricity improver in Jet fuel by liquid chromatography- electrospray ionization mass spectrometry. Chemistry Faculty Publications. 2014 12(3):22-5.

23. Yue L, Li G, He G, Guo Y, Xu L, Fang W. Impacts of hydrogen to carbon ratio ( H / C ) on fundamental properties and supercritical cracking performance of hydrocarbon fuels impacts of hydrogen to carbon ratio ( $\mathrm{H} / \mathrm{C}$ ) on fundamental properties and supercritical cracking performance of hydrocarbons. Chem Eng J. 2016;283:1216-23.

24. Xing $Y$, Xie W, Fang W, Guo Y, Lin R. Kinetics and product distributions for thermal cracking of a kerosene-based Aviation fuel. Energ Fuel. 2009;23(8):4021-4

25. Nakasaka Y, Nishimura J, Tago T, Masuda T. Deactivation mechanism of MFItype zeolites by coke formation during $n$-hexane cracking. Chem Eng J. 2015:278:159-65.

26. He S, Sun C, Yang X, Wang B, Dai X, Bai Z. Characterization of coke deposited on spent catalysts for long-chain-paraffin dehydrogenation. Chem Eng J. 2010;163(3):389-94.

27. Yu W, Yang W, Tay K, Zhao F. An optimization method for formulating model-based jet fuel surrogate by emulating physical, gas phase chemical properties and threshold sooting index (TSI) of real jet fuel under engine relevant conditions. Combustion Flame. 2018;193:192-217. 
28. D5001-10(2014) A. Standard Test Method for Measurement of Lubricity of Aviation Turbine Fuels by the Ball-on-Cylinder Lubricity Evaluator (BOCLE). ASTM Int. 2014;PA. Available from: www.astm.org. Accessed 14 Feb 2019.

29. Peyton KB. Fuel lubricity improver. Nalco Champion Fuel Field Manual, Third Edition. McGraw Hill Professional, Access Engineering; 2017. Available from: https://www.accessengineeringlibrary.com:443/browse/ nalco-champion-fuel-field-manual-third-edition/c9780071848091ch06lev1 sec09. Accessed 20 Feb 2019.

30. Kalakul S, Eden MR, Gani R. The chemical product simulator - ProCAPD. Computer Aided Chemical Engin. 2017;40:979-84.

31. Lin BH, Shen BX, Zhao JG. A study on the prediction model for the lubricity of hydrogenated ultra-low sulfur diesel fuel. Energy Sources, Part A: Recovery, Utilization Environmental Effects. 2010;33(3):254-64.

32. Belotti P, Kirches C, Leyffer S, Linderoth J, Luedtke J, Mahajan A. Mixedinteger nonlinear optimization, mathematics and computer science division preprint ANL/MCS-P3060-1112, November 22, 2012. Available from: https:// www.mcs.anl.gov/papers/P3060-1112.pdf

33. Cataluña R, da Silva R. Effect of Cetane Number on Specific Fuel Consumption and Particulate Matter and Unburned Hydrocarbon Emissions from Diesel Engines. J Combustion. 2012. https://doi.org/10. 1155/2012/738940.

\section{Publisher's Note}

Springer Nature remains neutral with regard to jurisdictional claims in published maps and institutional affiliations.

Ready to submit your research? Choose BMC and benefit from:

- fast, convenient online submission

- thorough peer review by experienced researchers in your field

- rapid publication on acceptance

- support for research data, including large and complex data types

- gold Open Access which fosters wider collaboration and increased citations

- maximum visibility for your research: over $100 \mathrm{M}$ website views per year

At BMC, research is always in progress.

Learn more biomedcentral.com/submissions 